\title{
Influence of Attachment Anxiety on the Relationship between Loneliness and Depression among Long-Term Care Residents
}

\author{
Suthikarn Arunrasameesopa, Nahathai Wongpakaran * and Tinakon Wongpakaran \\ Department of Psychiatry, Faculty of Medicine, Chiang Mai University, Chiang Mai 50200, Thailand; \\ suthikarn.a@cmu.ac.th (S.A.); tinakon.w@cmu.ac.th (T.W.) \\ * Correspondence: nahathai.wongpakaran@cmu.ac.th; Tel.: +66-53-935422 (ext. 320); Fax: +66-53-935426
}

Citation: Arunrasameesopa, S.; Wongpakaran, N.; Wongpakaran, T. Influence of Attachment Anxiety on the Relationship between Loneliness and Depression among Long-Term Care Residents. Healthcare 2021, 9 , 1675. https://doi.org/10.3390/ healthcare 9121675

Academic Editor: Phyo Kyaw Myint

Received: 22 October 2021

Accepted: 29 November 2021

Published: 3 December 2021

Publisher's Note: MDPI stays neutral with regard to jurisdictional claims in published maps and institutional affiliations.

Copyright: (c) 2021 by the authors. Licensee MDPI, Basel, Switzerland. This article is an open access article distributed under the terms and conditions of the Creative Commons Attribution (CC BY) license (https:// creativecommons.org/licenses/by/ $4.0 /)$.

\begin{abstract}
Background: Attachment styles influence an individual's ability to maintain relationships throughout their lifespan. Insecure attachment has been associated with many aspects of mental health. The study aimed to explore the influence of attachment on loneliness and depression among old-age residents in long-term care facilities. Methods: A survey was conducted among residents from long term care facilities (LTC) in Thailand during the COVID-19 pandemic; 221 older people participated in the study. The mean aged was $73.60 \pm 7.45$ years old, and $57.5 \%$ female. All participants completed the Geriatric Depression Scale, the six-item revised version of the University of California Los Angeles Loneliness Scale, and the Revised Experience of Close Relationships questionnaire to measure depressive symptoms, loneliness, and attachment style. Hierarchical multiple regression analysis was performed to find the predictors for depressive symptoms. Results: In all, $40.7 \%$ of residents in LTC facilities experienced depression. Male sex, education, loneliness, and attachment anxiety predicted the increased level of depressive symptoms. Conclusion: Loneliness was confirmed to be significantly associated with depressive symptoms, and attachment anxiety was found to be a strong predicting factor of depressive symptoms. Intervention and research regarding reducing loneliness and attachment anxiety should be promoted in LTC settings.
\end{abstract}

Keywords: depressive; lonely; isolation; COVID-19; nursing home; old age; attachment style

\section{Introduction}

It has been estimated that about 700 million people worldwide are older people, and that number is estimated to double in 2050 [1]. Thailand is one of the countries in transition to Aged Society, and the population of older people is predicted to reach $30 \%$ of the total population by 2050 [2]. Changing the family structure from extended to nuclear family and having fewer children in Thai families [3] are creating challenges in caregiving for older adults [4]. The aging phenomenon can also be explained by "second demographic transition" [5]. Some have to stay in long-term care (LTC) facilities. The World Health Organization has recommended that to deal with this transition, key issues for public health actions are using the concept of a person-centered approach applied in long-term care (LTC) facilities, helping older people by reducing inequal opportunities to access to health care services, and ensuring autonomy, dignity, integrity, freedom and independence [6].

A systematic review study revealed that the prevalence of depression was 5 to $25 \%$ among residents in LTC homes [7]; in Thailand, it was found to be up to 23\% [8]. Many factors have been found to be associated with depression among residents in LTC settings [9-13], including psychological distress or fear related to COVID-19 during this pandemic [14]. Loneliness is one of the common factors experienced among older people, and associated with depression [13] and a lower quality of life of residents in LTC settings $[15,16]$. Loneliness is the subjective feeling of lacking intimate and close relationships to others [17]. Different measurements were developed according to different understandings about loneliness; The De Jong Gierveld Loneliness Scale (DJGLS) considers 
loneliness from three perspectives (types of loneliness, the perspective of time, and emotional aspects) [17]; the UCLA loneliness scale contains two dimensions, i.e., negatively and positively worded items [18]. Studies have shown that 11.6 to $85.3 \%$ of people living in LTC settings have experienced loneliness $[15,19]$. Factors associated with loneliness include living alone, being unsatisfied with life, being at risk for undernutrition, having mental problems, having a weak sense of coherence, and not having contact with neighbors [19]. For residents in LTC settings, investigators found that a lack of self-determination due to being institutionalized and having unfulfilled needs for meaningful relationships played crucial roles in loneliness [20]. In addition to the association with depression, loneliness could be a risk factor for subsequent cognitive impairment [21].

Despite the fact that loneliness is related to many factors and many interventions have been adopted to mitigate such feeling especially during the COVID-19 pandemic [22], one psychological construct related to loneliness that might not have been explored sufficiently is individual attachment style. Attachment has been associated with many aspects of mental health, especially loneliness and depression. Insecure attachment appears to be associated with depressive symptoms and loneliness among adults [23-27]. Attachment was also found to be related to suicidality in that attachment patterns predicted medical lethality, amplifying the levels of mental pain [28]. Attachment theory is mainly influenced by the work of John Bowlby and Mary Ainsworth, focusing on the relationship between infants and their mothers, then considering the consequence of their relationship and the long-term relationship to others throughout their lifespan [29]. Secure attachment brought people a sense of self-worth and self-confidence, and they were more likely to enjoy stable relationships [30]. On the contrary, insecure attachment style created low self-esteem, unstable relationships, difficulties regulating emotions, increased risk of feelings of loneliness or developing depression and psychological distress [31]. Attachment style is classified by secure attachment, fearful insecure attachment, preoccupied insecure attachment, and dismissive insecure attachment [32]. Few studies have been conducted regarding the role of attachment on psychopathology among older people. One study confirmed its importance, similar to what was found among younger people in that those higher levels of attachment anxiety significantly increased the suicide risk among older adults [33]. However, research in special settings such as LTC homes remains scarce. It would be interesting to learn how the existing attachment style of older adults residing in this setting affect easily aroused feelings of loneliness, influencing the development of depression. Our study aimed to explore depression, feelings of loneliness, and attachment style among older people in LTC settings in Thailand, and also the predictive ability of these independent variables on depression. We hypothesized, based on the developmentally theoretical underpinning and related research evidence, that both loneliness, attachment anxiety and attachment avoidance would significantly relate to depression.

\section{Subjects and Methods}

This constituted a cross-sectional observational study conducted in LTC settings in Thailand from December 2020 to July 2021. A single population proportion formula with an assumption of $95 \%$ confidence level, the expected proportion with $7 \%$ absolute precision (margin of error), 23\% previous prevalence of depression in LTC settings [8] and adjusted for finite population of 1292 and a nonacceptance rate of $15 \%$ were used to determine a minimum sample size of 145 .

\subsection{Participants}

We enrolled residents aged over 60 years in LTC homes who were able to communicate orally in Thai. The total number of residents in Thailand in 2021 was 1292 in 12 government's LTC homes all over Thailand [34]. The inclusion criteria included LTC residents who were: (1) aged 60 years old or higher, (2) able to understand and communicate in Thai, and (3) able to complete questionnaires on their own. We excluded residents who had: (1) weakness in the dominant hand, hearing loss or visual loss to a degree that interfered 
communication, (2) received a diagnosis of dementia, and/or (3) obtained a Mini-Cog score of less than 3 points [35,36]. Of 294 residents recruited, 247 participants were enrolled, 11 participants met the exclusion criteria, and 15 participants had incomplete data. Finally, we obtained 221 participants for this analysis (Figure 1). All the participants were asked to complete the questionnaires. Informed consent was obtained from all participants from the beginning before proceeding to further steps. This research was approved by the Ethics Committee of the Faculty of Medicine, Chiang Mai University, Thailand.

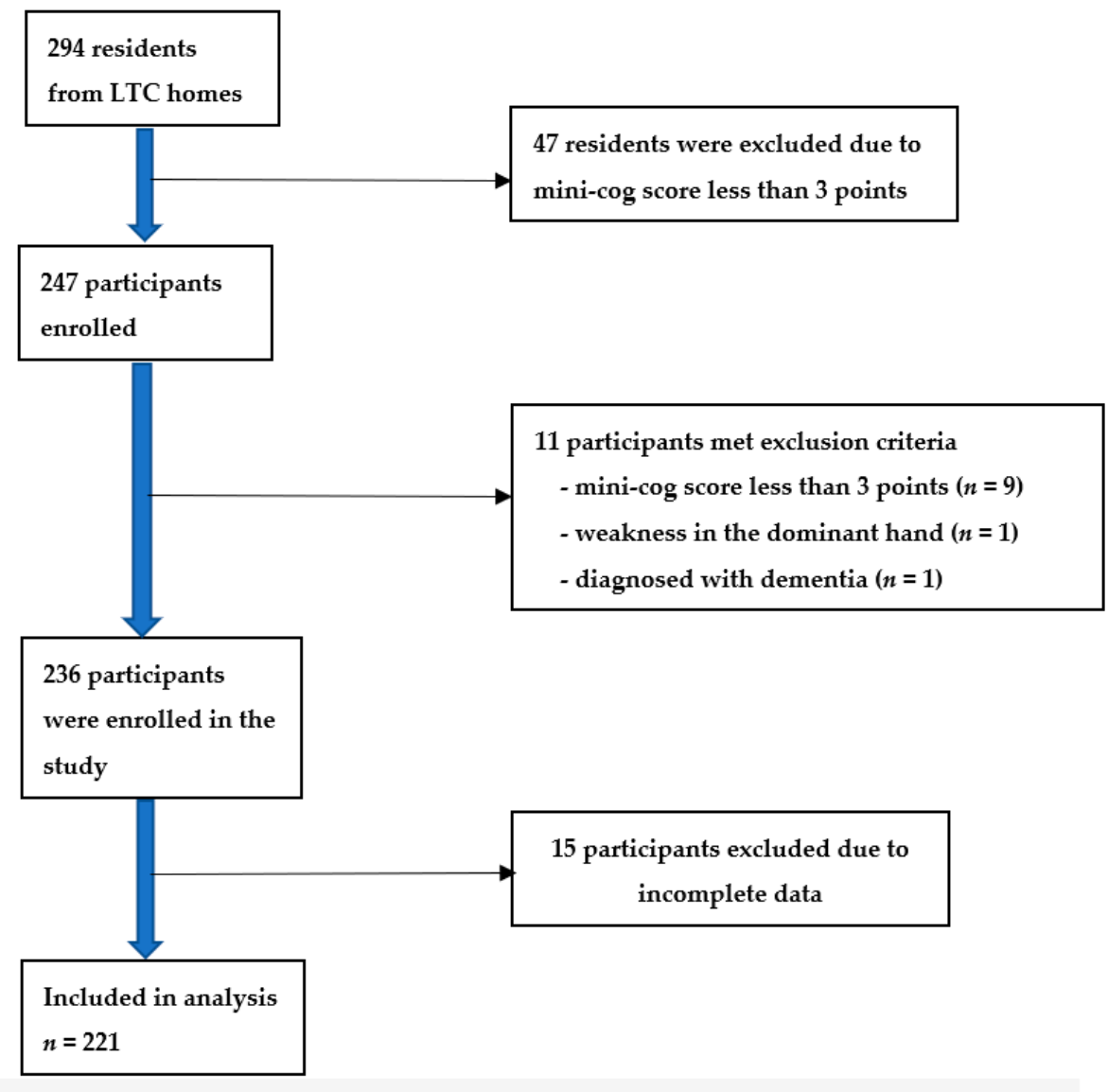

Figure 1. Flowchart of the study.

\subsection{Instruments}

The 18-item revised Experience of Close Relationships Questionnaire (ECR-R-18): This survey comprises a self-rating measurement assessing adult attachment style, yielding the scores of attachment anxiety and attachment avoidance [37]. It consists of 18 items: 9 questions for attachment anxiety and 9 questions for avoidance. Each question employs a 7-level Likert scale, where 1 is fully disagree, and 7 is fully agree. Higher scores indicate a higher level of anxiety or avoidance, and the scale is valid and reliable [38,39]. In this study, the Cronbach's alpha was 0.90 and 0.82 for anxiety and avoidance subscale, respectively.

The 6-item geriatric depression scale (GDS-6): This screening instrument for depression among older adults consists of 6 dichotomous-type ("Yes/No") questions to evaluate depressive symptoms the score ranges from 0 to 6 points. Higher scores indicate higher levels of depression [40]. The GDS cut-off score $\geq 2$, suggests depression [40] In this study, the Cronbach's alpha was 0.70 .

The Revised University of California Los Angeles Loneliness scale (RULS-6): This tool evaluates subjective feelings of loneliness and social isolation. It consists of 6 questions, with a score of 1 to 4 in each question, with 1 being never and 4 being often. Higher scores indicate higher levels of feelings of loneliness [41]. In this study, the Cronbach's alpha was 0.79. 
Mini-Cog: This tool is a brief cognitive screening test, which combines two parts i.e., a short-term memory test (the recall of 3 unrelated words-total 3 points) and the clock drawing test (total 2 points). The total scores range from 0 to 5 . Scores of 2 and lower indicate cognitive impairment $[35,36]$

\subsection{Statistical Analysis}

Descriptive statistics, e.g., frequency, percentage, mean and standard deviation, were used for demographic data, e.g., age, sex, years of education, marital status and measurement scores, i.e., ECR-R-18, GDS-6, and RULS-6. Pearson correlations were analyzed to correlate between measurement scores. Pair variables significantly correlating with $p<0.05$ were used for multiple regression. Hierarchical multiple regression was analyzed to demonstrate how each predictor affected the depressive outcome when holding all other predictors constant. In this case, we endeavored to see how the impact of loneliness on depression would change when attachment was considered in the models. We began with demographic data, i.e., sex, age, and education, as predictors in the first model, followed by the RULS score in the second model. Finally, ECR-R anxiety scores and ECR-R avoidance scores were added in the third model. The $\mathrm{R}$ square change was used to demonstrate the effect of the new set of predictors when they were added into the model. The R square change, significantly greater than zero, was inferred to have incremental predictive power. The R square change (increment) from Model 1 to Model 2 was computed as $\Delta R^{2}=$ Model $2 \mathrm{R}^{2}$-Model1 $\mathrm{R}^{2}$. The same rule was applied to Model 3. Statistical significance was set at $<0.05$ and all analyses were performed using IBM SPSS, Version 22.

\section{Results}

In total, 221 participants completed the questionnaire. A total of 127 participants were female $(57.5 \%)$ with a mean age of 73.60 years $(S D=7.45)$. Most participants' marital status was single $(44.8 \%)$. The mean score of attachment-anxiety was 3.92 and of attachmentavoidance was 3.39. The mean GDS score was $2.71(\mathrm{SD}=1.22)$. Depression based on GDS cut-off were found among 90 participants (40.7\%). The demographic and clinical data are shown in Table 1.

Table 2 shows the zero-order correlation between variables. Male sex was positively related to GDS scores $(\mathrm{r}=-0.22, p<0.01)$, whereas education was negatively associated with GDS scores. As expected, GDS was positively associated with RULS $(p<0.001)$. ECR-R anxiety but not ECR-R avoidance was associated with GDS, RULS, and age $(p<0.01)$

We analyzed hierarchical multiple regression to predict depression by attachment avoidance, attachment anxiety and loneliness. Demographic variables were entered as covariates on Step 1. Male sex was a significantly positive predictor for depression, whereas education was a negative predictor in Model $1(\beta=-0.19, p<0.01 ; \beta=-0.19, p<0.01$, respectively). RULS scores were added in a second step, and significantly predicted the GDS score $(\beta=0.33, p<0.001)$. R2 significantly increased in Model 2 compared with Model $1(0.11, p<0.001)$. ECRR-anxiety scores were added in the third step and found to be a significant additional predictor of depression $(\beta=0.25, p<0.001)$. R2 significantly increased in Model 3 compared with Model $2(0.05, p<0.001)$. Lastly, we added ECRR-avoidance, but did not predict the GDS score $(\beta=0.11, p \geq 0.05)$. R2 did not significantly change in Model 4 from Model $3(0.009, p=0.109)$. The R2 increased from $7 \%$ in the Model 1 to $23 \%$ in the final model (Table 3) 
Table 1. Participants' characteristics $(N=221)$.

\begin{tabular}{ll}
\hline Variable & $N(\%) /$ Mean \pm SD \\
\hline Socio-demographic & \\
\hline Age, Mean (SD) & $73.60 \pm 7.45$ \\
\hline Sex, $N$ (\% female) & $127(57.5)$ \\
\hline Education (years),Mean (SD) & $6.87 \pm 4.53$ \\
\hline Marital status, $N(\%)$ & \\
\hline Single & $99(44.8)$ \\
\hline Married & $11(5)$ \\
\hline Divorced & $27(12.2)$ \\
\hline Widowed & $83(37.6)$ \\
\hline No data & $1(0.4)$ \\
\hline Occupation, $N$ (\%) & \\
\hline Employee & $85(38.5)$ \\
\hline Government officer & $19(8.6)$ \\
\hline Personal business & $31(14)$ \\
\hline Unemployed & $76(34.4)$ \\
\hline Other & $10(4.5)$ \\
\hline Clinical data & $3.92 \pm 1.43$ \\
\hline ECR-R anxiety, Mean \pm SD & $2.71 \pm 1.22$ \\
\hline ECR-R avoidance, Mean \pm SD & $90(40.7)$ \\
\hline GDS total, Mean \pm SD & $13.67 \pm 4.19$ \\
\hline Depression based on GDS cut-off, $N(\%)$ & \\
\hline RULS, Mean \pm SD & \\
\hline Not & \\
\hline
\end{tabular}

Note: ECR-R, 18-item revised Experience of Close Relationships Questionnaire; GDS, the geriatric depression scale; RULS, the Revised University of California Los Angeles Loneliness Scale.

Table 2. Correlation matrix.

\begin{tabular}{llllllll}
\hline Variable & $\mathbf{1}$ & $\mathbf{2}$ & $\mathbf{3}$ & $\mathbf{4}$ & $\mathbf{5}$ & $\mathbf{6}$ & $\mathbf{7}$ \\
\hline 1.Sex & 1 & $0.28^{* * *}$ & 0.02 & 0.03 & $-0.22^{* *}$ & -0.05 & -0.13 \\
\hline 2.Age & 1 & 0.05 & 0.11 & -0.11 & 0.02 & $-0.19^{* *}$ \\
\hline 3.Education & & & 1 & -0.04 & $-0.17^{*}$ & -0.01 & -0.12 \\
\hline 4.RULS & & & 1 & $0.39^{* * *}$ & 0.06 & $0.20^{* *}$ \\
\hline 5.GDS & & & & 1 & -0.00 & $0.35^{* * *}$ \\
\hline 6.ECRR-avoidance & & & & & 1 & $-0.44^{* * *}$ \\
\hline 7.ECRR-anxiety & & & & & & & 1
\end{tabular}

${ }^{*} p<0.05 ;{ }^{* *} p<0.01 ;{ }^{* * *} p<0.001$, Note: ECR-R, 18-item revised Experience of Close Relationships Questionnaire; GDS, the geriatric depression scale; RULS, the Revised University of California Los Angeles Loneliness Scale.

Table 3. Hierarchical regression of attachment and loneliness in depression.

\begin{tabular}{lllllllllllll}
\hline Predictor & Model 1 & \multicolumn{3}{c}{ Model 2 } & \multicolumn{3}{c}{ Model 3 } & \multicolumn{3}{c}{ Model 4 } \\
\hline & B & $\boldsymbol{\beta}$ & SE & B & $\boldsymbol{\beta}$ & SE & B & $\beta$ & SE & B & $\beta$ & SE \\
\hline Sex & -0.56 & $-0.19^{* *}$ & 0.20 & -0.56 & $-0.19^{* *}$ & 0.19 & -0.50 & $-0.17^{* *}$ & 0.18 & -0.47 & $-0.16^{*}$ & 0.18 \\
\hline Age (years) & -0.01 & -0.05 & 0.01 & -0.02 & -0.09 & 0.01 & -0.01 & -0.04 & 0.01 & -0.01 & -0.04 & 0.01 \\
\hline $\begin{array}{l}\text { Education } \\
\text { (years) }\end{array}$ & -0.06 & $-0.19^{* *}$ & 0.02 & -0.06 & $-0.17^{* *}$ & 0.02 & -0.05 & $-0.15^{*}$ & 0.02 & -0.05 & $-0.14^{*}$ & 0.02 \\
\hline
\end{tabular}


Table 3. Cont.

\begin{tabular}{|c|c|c|c|c|c|c|c|c|c|c|}
\hline \multirow{2}{*}{$\begin{array}{l}\text { Predictor } \\
\text { RULS }\end{array}$} & \multirow[t]{2}{*}{ Model 1} & \multicolumn{3}{|c|}{ Model 2} & \multicolumn{3}{|c|}{ Model 3} & \multicolumn{3}{|c|}{ Model 4} \\
\hline & & 0.69 & $0.33^{* * *}$ & 0.13 & 0.58 & $0.28^{* * *}$ & 0.13 & 0.54 & $0.26^{* * *}$ & 0.13 \\
\hline ECRR-anxiety & & & & & 0.25 & $0.25^{* * *}$ & 0.06 & 0.31 & $0.30^{* * *}$ & 0.07 \\
\hline $\begin{array}{l}\text { ECRR- } \\
\text { avoidance }\end{array}$ & & & & & & & & 0.13 & 0.11 & 0.08 \\
\hline $\mathrm{R}^{2}$ & 0.07 & 0.18 & & & 0.23 & & & 0.23 & & \\
\hline $\mathrm{R}^{2}$ change & 0.08 & 0.11 & & & 0.05 & & & 0.009 & & \\
\hline
\end{tabular}

Model 1 included demographic variables, Model 2 included loneliness, Model 3 included demographic, loneliness, and attachment anxiety, and Model 4 included demographic, loneliness, attachment anxiety, and attachment avoidance; sex: male $=1$, female $=2,{ }^{*} p<0.05$; ${ }^{* *} p<0.01 ;{ }^{* * *} p<0.001, \mathrm{~B}=$ unstandardized regression coefficient, $\beta=$ standardized regression coefficient, $\mathrm{SE}=$ standard error.

\section{Discussion}

This study aimed to explore the prevalence of depression and examine how depression was influenced by loneliness, and attachment among older adults residing in LTC homes. Depression was found in $40.7 \%$ of residents in LTC homes, which was relatively high. Related studies have revealed a wide range in the prevalence of depression among residents in LTC homes, 5 and $82 \%$, and usually higher than in the community [7,42-47]. Compared with the report of the prevalence of $23 \%$ of depression in LTC homes in our previous study, and $23.7 \%$ in a tertiary care setting $[8,48]$, the present result was strikingly high during the COVID-19 pandemic. This supports the prior research [49].

In contrast to many studies, we have found that males experienced higher depression than females. Providing an easy explanation for this contradicting result would be difficult compared with the prior evidence that females were more likely to experience depression. One assumption has to do with the COVID-19 situation. Quite possibly, the stressful event of social isolation and any measure used regarding COVID-19 prevention could psychologically impact males more than females in LTC homes [50,51]. However, undetermined factors might be involved, needing further study.

As expected, subjects with low education levels were more likely to develop depression, but this was not the case for age, as found in other studies [43,52-56]. This could be because most participants were less old, and the range of age distribution was narrow compared to other related studies. In terms of loneliness, the relationship between loneliness and depression in LTC homes remained during the COVID-19 pandemic [57-59]. During the COVID-19 pandemic, the depression rate increased as social isolation would aggravate the feelings of loneliness, rendering the eventual depression outcome $[49,60]$.

The relationship between loneliness and depression was, however, lessened when attachment was added to the model. Our findings indicated that only a high level of attachment anxiety, but not attachment avoidance, predicted the increase in depression. Attachment anxiety represents a fearful style or preoccupied style and explained the increased variance of depression from 18 to $23 \%$. The fact that attachment anxiety (fearful or preoccupied style) but not attachment avoidance (dismissing style) was associated with depression was consistent with some related studies [25,61]. Some investigators found that fearful attachment and preoccupied attachment were associated with depression through neediness. A dismissive style was unrelated to neediness; hence, it did not predict depression [62]. Moreover, attachment anxiety may have been linked with depression through low self-esteem [63], and also through interpersonal sensitivity [64].

Various interventions, especially psychological therapies and leisure/skill development interventions, are provided to help reduce loneliness [65]. Some researchers suggest active coping strategies with culturally based or religious reliance, and social engagement with peers can be incorporated in healthcare services and social programs to assist these older adults [66]. Moreover, psychosocial interventions such as reminiscence therapy, support groups, or videoconferences are positive ways to create a social connection to improve loneliness and depression among residents in LTC homes [67]. 
The present results suggested that methods or strategies should be combined with the approach for attachment insecurity. Basically, individuals with preoccupied attachment usually express their desire to feel wanted. They may require frequent reassurance and approval. That can create burdens on others or caregivers and make it difficult to maintain. People with fearful attachment are even more difficult to deal with. They still want relationships and may actively search for them. However, when the relationship becomes too committed, the person with a fearful avoidant attachment may respond by simply running away from the relationship [68]. Therefore, understanding and helping individuals to cope with stress and loneliness based on the understanding of the attachment concept would be important [69]. For example, staff and caregivers in LTC homes may be aware of the importance of constant reassurance or appropriate approaches while providing intervention for combatting loneliness. However, intervention incorporated with the attachment concept specifically designed to deal with loneliness should experiment in further research.

\section{Limitations}

This study constitutes one of the first to study attachment style associated with loneliness and depression in LTC homes. Some limitations to be addressed are discussed below. We collected information from participants during the COVID-19 pandemic, making it difficult to process and collect data from participants because preventive measures in COVID-19, such as maintaining a physical distance, were applied, resulting in time limitations in this process. Second, we established inclusion criteria that specified only people able to communicate orally in Thai and having intact hearing or vision.

\section{Conclusions}

Nearly one half of residents in LTC facilities experienced depression, which was related to loneliness. Attachment style, developed during the early years of life, remained a critical psychological process among older adults. Attachment anxiety was found to be the strongest predictor among all independent variables in predicting depressive symptoms. The application of the results to provide intervention for older adults with depressive feelings only based on their anxious attachments was discussed.

Replication studies in different cultures are encouraged. Finding out whether the COVID-19 pandemic has an influence on the relation among these variables may be of benefit. Further study regarding intervention to reduce loneliness among LTC home residents may also be warranted.

Author Contributions: Conceptualization, S.A., N.W., and T.W.; methodology, T.W. and N.W.; software, T.W. and N.W.; validation, S.A., N.W., and T.W.; formal analysis, S.A., N.W., and T.W.; investigation, N.W. and S.A.; resources, N.W. and S.A.; data curation, S.A.; writing-original draft preparation, S.A., N.W., and T.W.; writing-review and editing, S.A., N.W., and T.W.; visualization, N.W. and T.W.; supervision, N.W.; project administration, N.W. and S.A.; funding acquisition, N.W. All authors have read and agreed to the published version of the manuscript.

Funding: This research was supported by the Faculty of Medicine, Chiang Mai University (Grant no. 025/2564). The funders had no role in study design, data collection and analysis, decision to publish, or preparation of the manuscript.

Institutional Review Board Statement: This study was approved by the research ethics committee of the Faculty of Medicine, Chiang Mai University (protocol code PSY-2563-07567 and date of approval: 2 October 2020).

Informed Consent Statement: Informed consent was obtained from all subjects involved in the study. Written informed consent has been obtained from the subjects to publish this paper.

Data Availability Statement: The datasets used and/or analyzed during the current study are available from the corresponding author upon reasonable request. 
Acknowledgments: We are thankful to all participants and our research assistants in data collecting process.

Conflicts of Interest: The authors declare no conflict of interest.

\section{References}

1. United Nations. World Population Aging. Available online: https://www.un.org/en/development/desa/population/ publications/pdf/ageing/WorldPopulationAgeing2019-Highlights.pdf (accessed on 18 November 2021).

2. World Health Organization. Older Population and Health System: A Profile of Thailand. Available online: https://www.who. int/ageing/projects/intra/phase_one/alc_intra1_cp_thailand.pdf (accessed on 18 November 2021).

3. Wongboonsin, K.; Guest, P.; Prachuabmoh, V. Demographic change and the demographic dividend in Thailand. Asian Popul. Stud. 2005, 1, 245-256. [CrossRef]

4. Boonyaratkalin, P. Long-term Care for the Dependent Elderly in the Community: The Nurse's role. In Thai Red Cross Nursing Journal; OECD Publishing: Paris, France, 2018.

5. Van de Kaa, D.J. The idea of a second demographic transition in industrialized countries. Birth 2002, 35, 45.

6. World Health Organization. World Report on Ageing and Health. Available online: https://apps.who.int/iris/handle/10665/18 6463 (accessed on 18 November 2021).

7. Seitz, D.; Purandare, N.; Conn, D. Prevalence of psychiatric disorders among older adults in long-term care homes: A systematic review. Int. Psychogeriatr. 2010, 22, 1025-1039. [CrossRef] [PubMed]

8. Wongpakaran, N.; Wongpakaran, T. Prevalence of major depressive disorders and suicide in long-term care facilities: A report from northern Thailand. Psychogeriatrics 2012, 12, 11-17. [CrossRef] [PubMed]

9. Sato, R.; Sawaya, Y.; Shiba, T.; Hirose, T.; Sato, M.; Ishizaka, M. Malnutrition is associated with depression in Japanese older adults requiring long-term care or support. J. Phys. Ther. Sci. 2021, 33, 585-590. [CrossRef] [PubMed]

10. Wang, F.; Liu, S.; Zhang, Q.; Ng, C.H.; Cui, X.; Zhang, D.; Xiang, Y.T. Prevalence of Depression in Older Nursing Home Residents in High and Low Altitude Regions: A Comparative Study. Front. Psychiatry 2021, 12, 669234. [CrossRef] [PubMed]

11. Chau, R.; Kissane, D.W.; Davison, T.E. Risk Factors for Depression in Long-Term Care: A Systematic Review. Clin. Gerontol. 2019, 42, 224-237. [CrossRef]

12. Arrieta, H.; Rezola-Pardo, C.; Echeverria, I.; Iturburu, M.; Gil, S.M.; Yanguas, J.J.; Irazusta, J.; Rodriguez-Larrad, A. Physical activity and fitness are associated with verbal memory, quality of life and depression among nursing home residents: Preliminary data of a randomized controlled trial. BMC Geriatr. 2018, 18, 80. [CrossRef]

13. Horwath, U.; Szczerbińska, K. Determinants of late-life depression in residents of long-term care facility. Pol. Merkur. Lekarski 2017, 43, 213-219.

14. Srifuengfung, M.; Thana-Udom, K.; Ratta-Apha, W.; Chulakadabba, S.; Sanguanpanich, N.; Viravan, N. Impact of the COVID-19 pandemic on older adults living in long-term care centers in Thailand, and risk factors for post-traumatic stress, depression, and anxiety. J. Affect. Disord. 2021, 295, 353-365. [CrossRef]

15. Zafar, J.; Malik, N.I.; Atta, M.; Makhdoom, I.F.; Ullah, I.; Manzar, M.D. Loneliness may mediate the relationship between depression and the quality of life among elderly with mild cognitive impairment. Psychogeriatrics 2021, 21, 805-812. [CrossRef]

16. Chang, H.K.; Gil, C.R.; Kim, H.J.; Bea, H.J. Factors Affecting Quality of Life Among the Elderly in Long-Term Care Hospitals. J. Nurs. Res. 2020, 29, e134. [CrossRef]

17. Rivero Jiménez, B.; Conde-Caballero, D.; Juárez, L.M. Loneliness Among the Elderly in Rural Contexts: A Mixed-Method Study Protocol. Int. J. Qual. Methods 2021, 20, 1609406921996861. [CrossRef]

18. Russell, D. UCLA Loneliness Scale (Version 3): Reliability, Validity, and Factor Structure. J. Personal. Assess. 1996, 66, 20-40. [CrossRef] [PubMed]

19. Tomstad, S.; Dale, B.; Sundsli, K.; Saevareid, H.I.; Söderhamn, U. Who often feels lonely? A cross-sectional study about loneliness and its related factors among older home-dwelling people. Int J. Older People Nurs 2017, 12, e12162. [CrossRef] [PubMed]

20. Paque, K.; Bastiaens, H.; Van Bogaert, P.; Dilles, T. Living in a nursing home: A phenomenological study exploring residents' loneliness and other feelings. Scand. J. Caring Sci. 2018, 32, 1477-1484. [CrossRef] [PubMed]

21. Cacioppo, S.; Grippo, A.J.; London, S.; Goossens, L.; Cacioppo, J.T. Loneliness: Clinical import and interventions. Perspect Psychol. Sci. 2015, 10, 238-249. [CrossRef]

22. Simard, J.; Volicer, L. Loneliness and Isolation in Long-term Care and the COVID-19 Pandemic. J. Am. Med. Dir. Assoc. 2020, 21, 966-967. [CrossRef]

23. Bifulco, A.; Moran, P.M.; Ball, C.; Bernazzani, O. Adult attachment style. I: Its relationship to clinical depression. Soc. Psychiatry Psychiatr. Epidemiol. 2002, 37, 50-59. [CrossRef]

24. Roberts, J.E.; Gotlib, I.H.; Kassel, J.D. Adult attachment security and symptoms of depression: The mediating roles of dysfunctional attitudes and low self-esteem. J. Pers. Soc. Psychol. 1996, 70, 310. [CrossRef]

25. Murphy, B.; Bates, G.W. Adult attachment style and vulnerability to depression. Pers. Individ. Differ. 1997, 22, 835-844. [CrossRef]

26. Carnelley, K.B.; Pietromonaco, P.R.; Jaffe, K. Depression, working models of others, and relationship functioning. J. Pers. Soc. Psychol. 1994, 66, 127. [CrossRef]

27. Erozkan, A. The attachment styles bases of loneliness and depression. Int. J. Psychol. Couns. 2011, 3, $186-193$. 
28. Levi-Belz, Y.; Gvion, Y.; Horesh, N.; Apter, A. Attachment patterns in medically serious suicide attempts: The mediating role of self-disclosure and loneliness. Suicide Life-Threat. Behav. 2013, 43, 511-522. [CrossRef] [PubMed]

29. Bretherton, I. The origins of attachment theory: John Bowlby and Mary Ainsworth. Dev. Psychol. 1992, 28, 759. [CrossRef]

30. Bowlby, J. The Making and Breaking of Affectional Bonds; Routledge: Abingdon-on-Thames, UK, 2012.

31. Ouellette, S.; DiPlacido, J. Personality's role in the protection and enhancement of health: Where the research has been, where it is stuck, how it might move. In Handbook of Health Psychology; Baum, A.S., Revenson, T.A., Singer, J.E., Eds.; Lawrence Erlbaum Associates: Mahwah, NJ, USA, 2001; pp. 175-193.

32. Ainsworth, M.D.S.; Blehar, M.C.; Waters, E.; Wall, S.N. Patterns of Attachment: A Psychological Study of the Strange Situation; Psychology Press: Hove, UK, 2015.

33. Oon-Arom, A.; Wongpakaran, T.; Satthapisit, S.; Saisavoey, N.; Kuntawong, P.; Wongpakaran, N. Suicidality in the elderly: Role of adult attachment. Asian J. Psychiatr. 2019, 44, 8-12. [CrossRef]

34. Department of Older Persons. Statistics of Older Persons who Use Services within the Social Welfare Development Center for Older Persons; Department of Older Persons: Bangkok, Thailand, 2020.

35. Borson, S.; Scanlan, J.M.; Chen, P.; Ganguli, M. The Mini-Cog as a screen for dementia: Validation in a population-based sample. J. Am. Geriatr. Soc. 2003, 51, 1451-1454. [CrossRef] [PubMed]

36. Trongsakul, S.; Lambert, R.; Clark, A.; Wongpakaran, N.; Cross, J. Development of the Thai version of Mini-Cog, a brief cognitive screening test. Geriatr. Gerontol. Int. 2015, 15, 594-600. [CrossRef]

37. Fraley, R.C.; Waller, N.G.; Brennan, K.A. An item response theory analysis of self-report measures of adult attachment. J. Pers. Soc. Psychol. 2000, 78, 350-365. [CrossRef]

38. Wongpakaran, T.; Wongpakaran, N. A short version of the revised 'experience of close relationships questionnaire': Investigating non-clinical and clinical samples. Clin. Pract. Epidemiol. Ment. Health 2012, 8, 36. [CrossRef] [PubMed]

39. Wongpakaran, T.; Wongpakaran, N.; Wannarit, K. Validity and reliability of the Thai version of the Experiences of Close Relationships-Revised questionnaire. SMJ 2011, 52, 100-106.

40. Wongpakaran, N.; Wongpakaran, T.; Kuntawong, P. Evaluating hierarchical items of the geriatric depression scale through factor analysis and item response theory. Heliyon 2019, 5, e02300. [CrossRef]

41. Wongpakaran, N.; Wongpakaran, T.; Pinyopornpanish, M.; Simcharoen, S.; Suradom, C.; Varnado, P.; Kuntawong, P. Development and validation of a 6-item Revised UCLA Loneliness Scale (RULS-6) using Rasch analysis. Br. J. Health Psychol. 2020, 25, 233-256. [CrossRef]

42. Pilania, M.; Yadav, V.; Bairwa, M.; Behera, P.; Gupta, S.D.; Khurana, H.; Mohan, V.; Baniya, G.; Poongothai, S. Prevalence of depression among the elderly (60 years and above) population in India, 1997-2016: A systematic review and meta-analysis. BMC Public Health 2019, 19, 832. [CrossRef]

43. Zou, C.; Chen, S.; Shen, J.; Zheng, X.; Wang, L.; Guan, L.; Liu, Q.; Yang, Y. Prevalence and associated factors of depressive symptoms among elderly inpatients of a Chinese tertiary hospital. Clin. Interv. Aging 2018, 13, 1755-1762. [CrossRef] [PubMed]

44. Zhang, H.-H.; Jiang, Y.-Y.; Rao, W.-W.; Zhang, Q.-E.; Qin, M.-Z.; Ng, C.H.; Ungvari, G.S.; Xiang, Y.-T. Prevalence of Depression Among Empty-Nest Elderly in China: A Meta-Analysis of Observational Studies. Front. Psychiatry 2020, 11, 608. [CrossRef]

45. Hoben, M.; Heninger, A.; Holroyd-Leduc, J.; Knopp-Sihota, J.; Estabrooks, C.; Goodarzi, Z. Depressive symptoms in long term care facilities in Western Canada: A cross sectional study. BMC Geriatr. 2019, 19, 335. [CrossRef]

46. Iden, K.R.; Engedal, K.; Hjorleifsson, S.; Ruths, S. Prevalence of Depression among Recently Admitted Long-Term Care Patients in Norwegian Nursing Homes: Associations with Diagnostic Workup and Use of Antidepressants. Dement. Geriatr. Cogn. Disord. 2014, 37, 154-162. [CrossRef] [PubMed]

47. Thakur, M.; Blazer, D.G. Depression in long-term care. J. Am. Med. Dir. Assoc. 2008, 9, 82-87. [CrossRef]

48. Wongpakaran, N.; Wongpakaran, T.; Lerttrakarnnon, P.; Jiraniramai, S.; Sirirak, T.; Assanangkornchai, S.; Taemeeyapradit, U.; Tantirangsee, N.; Lertkachatarn, S.; Arunpongpaisal, S.; et al. Prevalence, clinical and psychosocial variables of depression, anxiety and suicidality in geriatric tertiary care settings. Asian J. Psychiatr. 2019, 41, 38-44. [CrossRef] [PubMed]

49. Levere, M.; Rowan, P.; Wysocki, A. The Adverse Effects of the COVID-19 Pandemic on Nursing Home Resident Well-Being. J. Am. Med. Dir. Assoc. 2021, 22, 948-954.e942. [CrossRef]

50. Shi, L.; Lu, Z.A.; Que, J.Y.; Huang, X.L.; Liu, L.; Ran, M.S.; Gong, Y.M.; Yuan, K.; Yan, W.; Sun, Y.K.; et al. Prevalence of and Risk Factors Associated With Mental Health Symptoms Among the General Population in China During the Coronavirus Disease 2019 Pandemic. JAMA Netw. Open 2020, 3, e2014053. [CrossRef]

51. Li, Y.; Li, J.; Yang, Z.; Zhang, J.; Dong, L.; Wang, F.; Zhang, J. Gender Differences in Anxiety, Depression, and Nursing Needs Among Isolated Coronavirus Disease 2019 Patients. Front. Psychiatry 2021, 12, 2068. [CrossRef]

52. Barua, A.; Ghosh, M.K.; Kar, N.; Basilio, M.A. Socio-demographic Factors of Geriatric Depression. Indian J. Psychol. Med. 2010, 32, 87-92. [CrossRef] [PubMed]

53. Zhao, D.; Hu, C.; Chen, J.; Dong, B.; Ren, Q.; Yu, D.; Zhao, Y.; Li, J.; Huang, Y.; Sun, Y. Risk factors of geriatric depression in rural China based on a generalized estimating equation. Int. Psychogeriatr. 2018, 30, 1489-1497. [CrossRef]

54. Al-Shammari, S.A.; Al-Subaie, A. Prevalence and correlates of depression among Saudi elderly. Int. J. Geriatr. Psychiatry 1999, 14, 739-747. [CrossRef] 
55. Akhtar, H.; Khan, A.M.; Vaidhyanathan, K.V.; Chhabra, P.; Kannan, A.T. Socio-demographic Predictors of Depression among the Elderly Patients Attending Out Patient Departments of a Tertiary Hospital in North India. Int. J. Prev. Med. 2013, 4, 971-975. [PubMed]

56. Chang-Quan, H.; Zheng-Rong, W.; Yong-Hong, L.; Yi-Zhou, X.; Qing-Xiu, L. Education and risk for late life depression: A meta-analysis of published literature. Int. J. Psychiatry Med. 2010, 40, 109-124. [CrossRef] [PubMed]

57. Drageset, J.; Espehaug, B.; Kirkevold, M. The impact of depression and sense of coherence on emotional and social loneliness among nursing home residents without cognitive impairment-A questionnaire survey. J. Clin. Nurs. 2012, 21, 965-974. [CrossRef] [PubMed]

58. Fessman, N.; Lester, D. Loneliness and Depression among Elderly Nursing Home Patients. Int. J. Aging Hum. Dev. 2000, 51, 137-141. [CrossRef]

59. Prieto-Flores, M.E.; Forjaz, M.J.; Fernandez-Mayoralas, G.; Rojo-Perez, F.; Martinez-Martin, P. Factors associated with loneliness of noninstitutionalized and institutionalized older adults. J. Aging Health 2011, 23, 177-194. [CrossRef]

60. Franza, F.; Solomita, B.; Tavormina, G. Loneliness and Hopelesness: Their Role in the Depressive Cases during the COVID Pandemia. Psychiatr. Danub. 2021, 33, 14-17.

61. Dagnino, P.; Pérez, C.; Gómez, A.; Gloger, S.; Krause, M. Depression and Attachment: How do Personality Styles and Social Support Influence This Relation? Res. Psychother. 2017, 20, 237. [CrossRef]

62. Besser, A.; Priel, B. Attachment, depression, and fear of death in older adults: The roles of neediness and perceived availability of social support. Pers. Individ. Differ. 2008, 44, 1711-1725. [CrossRef]

63. Šare, S.; Ljubičić, M.; Gusar, I.; Čanović, S.; Konjevoda, S. Self-Esteem, Anxiety, and Depression in Older People in Nursing Homes. Healthcare 2021, 9, 1035. [CrossRef]

64. Stepp, S.D.; Morse, J.Q.; Yaggi, K.E.; Reynolds, S.K.; Reed, L.I.; Pilkonis, P.A. The role of attachment styles and interpersonal problems in suicide-related behaviors. Suicide Life Threat. Behav. 2008, 38, 592-607. [CrossRef] [PubMed]

65. Quan, N.G.; Lohman, M.C.; Resciniti, N.V.; Friedman, D.B. A systematic review of interventions for loneliness among older adults living in long-term care facilities. Aging Ment. Health 2020, 24, 1945-1955. [CrossRef]

66. Shorey, S.; Chan, V. The experiences and needs of Asian older adults who are socially isolated and lonely: A qualitative systematic review. Gerontol. Geriatr. 2021, 92, 104254. [CrossRef] [PubMed]

67. Mikkelsen, A.S.B.; Petersen, S.; Dragsted, A.C.; Kristiansen, M. Social Interventions Targeting Social Relations Among Older People at Nursing Homes: A Qualitative Synthesized Systematic Review. Inquiry 2019, 56, 46958018823929. [CrossRef]

68. Wongpakaran, N.; DeMaranville, J.; Wongpakaran, T. Validation of the Relationships Questionnaire (RQ) against the Experience of Close Relationship-Revised Questionnaire in a Clinical Psychiatric Sample. Healthcare 2021, 9, 1174. [CrossRef] [PubMed]

69. Wei, M.; Shaffer, P.A.; Young, S.K.; Zakalik, R.A. Adult attachment, shame, depression, and loneliness: The mediation role of basic psychological needs satisfaction. J. Couns. Psychol. 2005, 52, 591. [CrossRef] 